\title{
LA DEFENSORÍA DE LA COMUNIDAD
}

\author{
UNIVERSITARIA DE LA UNIVERSIDAD
}

\section{NACIONAL DE CORDOBA-REPÚBLICA}

\section{ARGENTINA}

\author{
Liliana Aguiar de Zapiola \\ Defensora de la Comunidad Universitaria \\ Universidad Nacional de Córdoba \\ República Argentina
}

Las dos caras de un mismo desafío: afianzamiento y expansión

Los dolores que quedan son las libertades que faltan

Manifiesto Liminar - Reforma Universitaria, junio 1918

\section{PRESENTACIÓN. UNA HISTORIA DE FRACTURAS}

En 1997, el Rectorado de la Universidad Nacional de Córdoba detecta irregularidades en actas de exámenes y títulos. Para resolver el grave problema el Rector conforma una comisión con miembros de la máxima autoridad colegiada de la institución (Honorable Consejo Superior) encargándole el análisis de tan delicada cuestión. Luego 
de una exhaustiva investigación de los hechos denunciados, la comisión propone, además del establecimiento de mecanismos específicos, la creación de un organismo de control permanente, así nace la Defensoría de la Comunidad Universitaria (en adelante, DCU). En el mismo año se dicta una resolución que establece funciones, facultades y limitaciones. Sea porque se toman antecedentes de otras defensorías universitarias o porque la intención de los consiliarios es ir más allá de la mera coyuntura, la DCU nace con una impronta amplia de defensa de los derechos individuales y colectivos de toda la comunidad universitaria. En un contexto de neo liberalismo a nivel nacional y de un Estado que avanza sobre la autonomía de las universidades ${ }^{1}$, el Consejo Superior le da la más amplia autonomía no dependiendo de autoridad alguna con la sola obligación de comunicar sus acciones al Alto Cuerpo. Transcurridos casi treinta años, la Defensoría de la Universidad Nacional de Córdoba es la única que existe en Argentina como organismo autónomo de cualquier otra autoridad universitaria ${ }^{2}$.

A partir de su creación, se pueden reconocer tres etapas que hablan de una historia de fracturas: Una inicial que hemos llamado fundacional incluye dos gestiones (19972003). Se toman las primeras medidas para difundir la institución y se inicia el trabajo de apoyo a la comunidad, firmándose convenios con la Defensoría del Pueblo de la Nación y la Defensoría de la Provincia de Córdoba. Por distintas razones ninguna de las dos Defensoras completa el período reglamentario de tres años. La Dra. Alicia Malanca, renuncia por cansancio moral en una sesión del Consejo Superior con fuertes acusaciones a las autoridades rectorales del momento; la Dra. Pierina Moreau, debe retirarse por sufrir una grave enfermedad. En 2004, se inicia una larga etapa de vacancia al no cubrirse el

\footnotetext{
${ }^{1}$ Entre otras, la Ley de Educación Superior de 1995 que limita la autonomía de las universidades al reglamentar cuestiones de estricta injerencia universitaria y no garantiza el financiamiento estatal.

2 Tanto la Universidad de Buenos Aires como la Universidad Nacional de Cuyo cuentan con oficinas para la defensa de los derechos de los estudiantes, no autónomas sino dependientes de otros organismos de gobierno de sus universidades.
} 
cargo por más de diez años (fines de 2003 a agosto 2014). La oficina sigue trabajando respondiendo a las consultas recibidas sin estar legitimada para abordar acciones proactivas. Finalmente, a mediados de 2014, se aprueba la designación de una Defensora con lo que comienza la etapa actual que esperamos se constituya en un período de afianzamiento y expansión.

\section{MARCAS DE IDENTIDAD}

La Defensoría de la Comunidad Universitaria de nuestra Universidad participa de características que en general definen a estas instituciones. Centralmente: su doble carácter de contralor institucional y defensa de derechos en el marco de una plena autonomía con relación al poder político y, como correlato, su autarquía administrativa y financiera. Al igual que en otros organismos hermanos, regulan su actuación los principios rectores de informalidad, confidencialidad, celeridad y desburocratización.

En el caso específico de la DCU cordobesa, algunas facultades podrían constituir marcas identitarias. Por una parte, se le encarga defender derechos que exceden los individuales e incluye los intereses difusos o colectivos de la comunidad universitaria. Adicionalmente, una segunda marca identitaria resulta de la amplitud de su ámbito de actuación que abarca cuatro claustros: docentes, estudiantes, graduados y nodocentes. Tal vez ello se deba a que, en cumplimiento de una de las banderas de la Reforma del 18 -el cogobierno tripartito y paritario-, los órganos colegiados de la UNC se componen, en los períodos democráticos, con representantes de tres claustros (docentes, estudiantes y graduados). Con la recuperación de la autonomía, después de la última dictadura militar, se incorpora también el claustro llamado nodocente (personal administrativo, profesional y de servicio) y, de este modo, el gobierno de la Universidad es, desde mediados de 1980, cuatripartito. En consonancia, la DCU actúa en resguardo de los derechos de cuatro 
claustros y, de acuerdo a nuestros registros, es la única defensoría universitaria que incluye al claustro de graduados.

Como organismo autónomo la DCU no forma parte del gobierno de la Universidad, si el término alude a instancias unipersonales o colegiadas responsables de la toma de decisiones al más alto nivel. Por el contrario, si algo la define por la negativa (como a otras instituciones análogas) es la carencia de facultades resolutivas. Mirada desde nuestra perspectiva, la podríamos definir como un servicio que se presta, en forma individual o colectiva, a los miembros de la comunidad universitaria y, en última instancia, a la Universidad si el concepto se entiende en sentido amplio concibiéndolo como acompañamiento, asesoramiento, representación...

¿Qué servicio presta la Defensoría a la Universidad? Sostenemos que contribuye a la gobernabilidad entendida como la capacidad de las autoridades universitarias para responder a las diferentes demandas, consolidar su legitimidad y propiciar proyectos que alimenten el imaginario que cohesiona los diferentes sectores e intereses de la comunidad. Aporta a la gobernabilidad en la medida que apunta a consolidar la democracia universitaria al defender los principios y derechos universitarios, incluyendo los

\section{intereses difusos o colectivos.}

Su autonomía y su relación con los cuatro claustros, la ubican en un lugar especialmente apto para acciones de mediación, para la resolución de los conflictos entre los miembros de la comunidad y entre sus demandas y las autoridades.

La DCU trabaja con cada una de las unidades académicas, adapta sus modos de acción al estilo político de cada una. La mayoría, más o menos abiertas al diálogo, acepta la comunicación personal; en otras, más burocráticas se requieren tramitaciones escritas; alguna, profundamente autoritaria, resiste la actuación de la DCU, no responde los pedidos de informes y dilata los pedidos de audiencia. 


\section{LA VIGENCIA DE UN DOBLE DESAFÍO}

a) Afianzamiento.

Dijimos que luego de casi treinta años de historia, la DCU de Córdoba no ha logrado su consolidación, tampoco ha sido protagonista de la expansión de la institución a otras universidades argentinas. En la necesidad de establecer prioridades, al asumir el cargo, nos planteamos la necesidad de, en una primera instancia, reposicionar a la Defensoría al interior de la Universidad. Para ello, visitamos todas las unidades académicas informando sobre los objetivos y acciones encaradas e indagando sobre los problemas relevantes en cada una. Se detectaron así temas que en forma recurrente preocupan a las distintas Facultades, centralmente: Asignaturas con resultados anómalos; Violencias de género; y, Derechos de autor en la Universidad. El tratamiento de estos temas en jornadas coordinadas por la DCU con miembros y autoridades de las distintas unidades académicas es pensado como una forma más de visibilizar a la DCU.

Pero el núcleo de nuestras políticas radica en la atención personalizada de cada consulta y el seguimiento sistemático hasta su resolución. Ello implica un gran esfuerzo del equipo que cuenta con una estructura muy pequeña: además de la Defensora, una persona a cargo de la Secretaría y Administración y un Asesor Legal. Sin embargo, estamos convencidos que esta forma de actuar es lo que más ha redundado en el conocimiento de nuestra oficina. Así, alrededor del setenta por ciento de quienes llegan a la oficina lo hace por recomendación de allegados, conocidos y aún de autoridades. Además, si comparamos el número de actuaciones en el primer semestre de 2014 (último período de acefalía) con este primer semestre de 2016 el aumento del número de consultas ha sido de un seiscientos por ciento aproximadamente. Por cierto, queda mucho por hacer 
porque en nuestra Universidad asisten unas ciento cuarenta mil personas de los cuatro claustros y podemos afirmar que un alto porcentaje aún no conoce la existencia de la Defensoría. Consideramos que, igual que el sistema democrático, una institución como la nuestra se habrá consolidado en la medida que el traspaso reglamentario de sus autoridades no presente hiatos temporales y crezca el número de quienes acuden a la Defensoría en defensa de sus derechos ampliando así la comunidad a la que ésta sirve.

\section{b) Expansión}

La otra cara del desafío que enfrenta la DCU es el de su expansión entre las Universidades de nuestro país y países vecinos. Hay en Argentina ciento ocho universidades entre públicas y privadas, pero en casi treinta años de existencia la institución no se ha expandido.

Del relevamiento del número de universidades y de defensorías en Latino América $^{3}$ surge que, sobre un total de mil doscientas universidades existen alrededor de ciento diez Defensorías Universitarias ${ }^{4}$. Si las consideramos en función del país de pertenencia, encontramos que los tres países con más proporción son: Brasil (54 ouvidurías sobre 230 universidades), Perú (19 sobre 142) y México (20 sobre 230). Tanto Brasil $^{5}$ como Perú ${ }^{6}$ disponen de normativas que, con distintos alcances, propician la creación de Defensorías. México no cuenta con apoyo de legislación pero desde la creación de la primera defensoría en nuestro subcontinente (1985, Universidad Nacional

\footnotetext{
${ }^{3}$ Los números son siempre provisorios y sujetos a revisión colectiva para elaborar una base de datos completa y fiable, tarea en la que se encuentra la conducción de la REDDU.

${ }^{4}$ Presentado en la asamblea del Instituto Latinoamericano del Ombudsman, Bs Aires, Argentina, 5/2016. ${ }^{5}$ Constitución de 1988, Art. 37, p3, Impone a todas las instituciones públicas, creación e implantación de formas de participación del usuario en la administración pública y mecanismos para el control de los servicios públicos. Ley 8.078 (Código de Defesa do Consumidor), 1990.

${ }^{6}$ Ley Universitaria № 30220, Cap. XVI, art. 133. Deja a las universidades su regulación.
} 
Autónoma de México) exhibe una larga trayectoria de trabajo sistemático por la expansión a otras Universidades de su país y por el estrechamiento de relaciones con otras redes y defensorías europeas y americanas. Ello seguramente ha redundado en su pronta consolidación y expansión. Ni la Ley de Educación Superior Argentina ni el Estatuto de la Universidad Nacional de Córdoba hacen alusión alguna a la Defensoría Universitaria.

En síntesis, una historia de fracturas, aún escasa presencia en el interior de la Universidad, nula expansión en el país y relaciones a consolidar en el exterior dan cuenta de las múltiples facetas a encarar para responder a las dos caras del desafío que la DCU cordobesa enfrenta: su afianzamiento y expansión.

Estas dificultades e incipientes logros nos llevan al principio. Iniciamos esta presentación con una frase del Manifiesto Liminar de la Reforma Universitaria nacida en Córdoba hace casi un siglo y que resuenan hoy con mucha vigencia.

Sabemos por nuestra tarea cotidiana que quedan dolores y faltan libertades ¿En otro contexto, son los mismos dolores y las mismas libertades de hace cien años? Desde nuestra doble condición de universitarios (profesores-investigadores) y defensores, apelamos a la construcción colectiva de conocimiento sobre la historia y la actualidad de nuestras instituciones. Estudios de casos, análisis comparativos, resultan un deber ineludible de las Defensorías Universitarias si se van a hacer cargo de su responsabilidad en la profundización de la democracia universitaria ${ }^{7}$.

\footnotetext{
${ }^{7}$ En esto nos hacemos eco de las palabras de Argimiro Rojo Salgado en Una aproximación a la institución del Defensor Universitario: El caso español. Encuentro REDDU, 2012, México.
} 